\title{
FBI-1 Is Overexpressed in Gestational Trophoblastic Disease and Promotes Tumor Growth and Cell Aggressiveness of Choriocarcinoma via PI3K/Akt Signaling
}

Victor C.Y. Mak, ${ }^{*}$ Oscar G.W. Wong, ${ }^{*}$ Michelle K.Y. Siu, ${ }^{\dagger}$ Esther S.Y. Wong, ${ }^{*}$ Wai-Yan Ng, ${ }^{*}$ Richard W.C. Wong, ${ }^{*}$ Ka-Kui Chan, ${ }^{*}$ Hextan Y.S. Ngan, ${ }^{\dagger}$ and Annie N.Y. Cheung*

From the Departments of Pathology* and Obstetrics and Gynaecology, ${ }^{\dagger}$ University of Hong Kong, Hong Kong, China

Accepted for publication

March 2, 2015.

Address correspondence to Annie N.Y. Cheung, M.D., Ph.D., Department of Pathology, University of Hong Kong, Queen Mary Hospital, Pokfulam Rd., Hong Kong, China. E-mail: anycheun@hkucc. hku.hk.

\begin{abstract}
Human placental trophoblasts can be considered pseudomalignant, with tightly controlled proliferation, apoptosis, and invasiveness. Gestational trophoblastic disease (GTD) represents a family of heterogeneous trophoblastic lesions with aberrant apoptotic and proliferative activities and dysregulation of cell signaling pathways. We characterize the oncogenic effects of factor that binds to the inducer of short transcripts of HIV-1 [FBI-1, alias POZ and Krüppel erythroid myeloid ontogenic factor (POKEMON)/ ZBTB7A] in GTD and its role in promoting cell aggressiveness in vitro and tumor growth in vivo. IHC studies showed increased nuclear expression of FBI-1, including hydatidiform moles, choriocarcinoma (CCA), and placental site trophoblastic tumor, in GTD. In JAR and JEG-3 CCA cells, ectopic FBI-1 expression opposed apoptosis through repression of proapoptotic genes (eg, BAK1, FAS, and CASP8). FBI-1 overexpression also promoted Akt activation, as indicated by Akt-pS473 phosphorylation. FBI-1 overexpression promoted mobility and invasiveness of JEG-3 and JAR, but not in the presence of the phosphoinositide 3-kinase inhibitor LY294002. These findings suggest that FBI-1 could promote cell migration and invasion via phosphoinositide 3-kinase/Akt signaling. In vivo, nude mice injected with CCA cells with stable FBI-1 knockdown demonstrated reduced tumor growth compared with that in control groups. These findings suggest that FBI-1 is clinically associated with the progression of, and may be a therapeutic target in, GTD, owing to its diverse oncogenic effects on dysregulated trophoblasts. (Am J Pathol 2015, 185: 2038-2048; http://dx.doi.org/10.1016/j.ajpath.2015.03.011)
\end{abstract}

Gestational trophoblastic disease (GTD) is a group of heterogeneous trophoblastic lesions including hydatidiform moles (partial mole and complete mole) that carry malignant potential, as well as frankly malignant tumors such as choriocarcinoma (CCA), placental site trophoblastic tumor, and epithelioid trophoblastic tumor. ${ }^{1,2}$ Although they are distinct diseases, about half of CCA cases are preceded by hydatidiform mole. In fact, although most cases of hydatidiform mole may regress after suction evacuation, $8 \%$ to $30 \%$ of cases of hydatidiform mole may develop into persistent trophoblastic neoplasm that requires chemotherapy. ${ }^{1,3}$ In recent years, hyperactivation of proto-oncogenic cell signaling pathways, such as the p21-activated kinases, leading to aggressive outcome in GTD patients, has been reported. ${ }^{4,5}$ In addition,
GTD has also been characterized by abnormal proliferation and apoptosis. 6,7

Although TP53 is commonly mutated in human malignancies, lack of TP53 mutation has been reported in hydatidiform mole and $\mathrm{CCA} .{ }^{8}$ Findings from our recent studies of apoptosis-stimulating protein of p53 1 and 2, DJ-1, and phosphatase and tensin homologue suggest that these p53 regulators and mediators may have a crucial

Supported by General Research Fund from the Research Grant Council of the Hong Kong Special Administrative Region HKU 763211 (A.N.C.).

Disclosures: None declared.

Portions of this work were published in the MMedSc thesis of W.-Y.N. and in the doctoral thesis of V.C.Y.M. 
Table 1 Primers Used for Real-Time Quantitative PCR

\begin{tabular}{|c|c|}
\hline Primer name & Sequences \\
\hline \multirow[t]{2}{*}{ FBI-1 } & F: $5^{\prime}-$ TCTGCGAGAAGGTCATCC-3' \\
\hline & R: 5'-CGTAGTTGTGGGCAAAGG-3' \\
\hline \multirow[t]{2}{*}{ GAPDH } & F: 5'-TCCATGACAACTTTGGTATCGCG-3' \\
\hline & R: 5'-ACAGTCTTCTGGGTGGCAGTG-3' \\
\hline \multirow[t]{2}{*}{$18 \mathrm{~S}$} & F: 5'-GTAACCCGTTGAACCCCATT-3' \\
\hline & R: 5'-CCATCCAATCGGTAGTAGCG-3' \\
\hline \multirow[t]{2}{*}{ Fas } & F: 5'-CTCCAAGGGATTGGAATTGA-3' \\
\hline & R: 5'-GACAAAGCCACCCCAAGTTA-3' \\
\hline \multirow[t]{2}{*}{ FasL } & F: 5'-TCAATGAAACTGGGCTGTACTTT-3' \\
\hline & R: 5'-AGAGTTCCTCATGTAGACCTTGT-3' \\
\hline \multirow[t]{2}{*}{ TRAF2 } & F: 5'-CTGACTTGGAGCAGAAGG-3' \\
\hline & R: 5'-GCCGTTCAGGTAGATACG-3' \\
\hline \multirow[t]{2}{*}{ TRADD } & F: 5'-TTCTGCGGCTATTGCTGA-3' \\
\hline & R: 5'-TGAAACTGTAAGGGCTGG-3' \\
\hline \multirow[t]{2}{*}{ Caspase-8 } & F: 5'-CCGCAAAGGAAGCAAGAAC- $3^{\prime}$ \\
\hline & R: 5'-АATTCTGATCTGCTCACTTCTTCTG-3' \\
\hline \multirow[t]{2}{*}{ Caspase-10 } & F: 5'-CAGAAGGCATTGACTCAGAGAACT-3' \\
\hline & R: 5'-GATACGACTCGGCTTCCTTGT-3' \\
\hline \multirow[t]{2}{*}{ Bcl-x } & F: 5'-GCAGGTATTGGTGAGTCGGATCGC-3' \\
\hline & R: $5^{\prime}-\mathrm{CACAAAAGTATCCCAGCCGCCG-3^{ \prime }}$ \\
\hline \multirow[t]{2}{*}{ Bcl-2 } & F: 5'-GGTGGTGGAGGAACTCTTCA-3' \\
\hline & R: 5'-ACCTACCCAGCCTCCGTTAT-3' \\
\hline \multirow[t]{2}{*}{ Survivin } & F: 5'-ATTCGTCCGGTTGCGCTTTCC-3' \\
\hline & R: 5'-CACGGCGCACTTTCTTCGCAG-3' \\
\hline \multirow[t]{2}{*}{ BAK } & F: 5'-GAACAGGAGGCTGAAGGGGT-3' \\
\hline & R: 5'-TCAGGCCATGCTGGTAGACG- $3^{\prime}$ \\
\hline \multirow[t]{2}{*}{ BAX } & F: 5'-TGCAGAGGATGATTGCTGAC- $3^{\prime}$ \\
\hline & R: 5'-GGAGGAAGTCCAGTGTCCAG-3' \\
\hline \multirow[t]{2}{*}{ Caspase-9 } & F: 5'-TTCCCAGGTTTTGTCTCCTG-3' \\
\hline & R: 5'-GGGACTGCAGGTCTTCAGAG-3' \\
\hline \multirow[t]{2}{*}{ PARP } & F: 5'-AGGCTGCTTTGTCAAGAA-3' \\
\hline & R: 5'-CTTGCTGCTTGTTGAAGAT-3' \\
\hline \multirow[t]{2}{*}{ Caspase-7 } & F: 5'-GGAGAAAGCTCATGGCTGTGT-3' \\
\hline & R: 5'-TCCCCTTGGCTGTGTTTTG-3' \\
\hline \multirow[t]{2}{*}{ Caspase-3 } & F: 5'-CTGGACTGTGGCATTGAGACA-3' \\
\hline & R: 5'-AGTCGGCCTCCACTGGTATTT-3' \\
\hline \multirow[t]{2}{*}{$\mathrm{p} 110 \alpha$} & F: 5'-GTATGTCTATCCTCCAAATGTGAG-3' \\
\hline & R: 5'-CACAGTCATGGTTGATTTTCAGAG-3' \\
\hline \multirow[t]{2}{*}{$\mathrm{p} 85 \alpha$} & F: 5'-AGGTCGCCTAGCATACCTCA-3' \\
\hline & R: $5^{\prime}$-AGAGCTGGCTGCTGAGAATC-3' \\
\hline \multirow[t]{2}{*}{$\mathrm{p} 85 \beta$} & F: 5'-CGAGACCAGTACCTCGTGTG-3' \\
\hline & R: 5'-TAATCCCCAGCCACTCGTT-3' \\
\hline \multirow[t]{2}{*}{ PTEN } & F: 5'-TGACAGCCATCATCAAAGAGA-3' \\
\hline & R: 5'-TGCTTTGAATCCAAAAACCTT-3' \\
\hline
\end{tabular}

$\mathrm{BAK}, \mathrm{BCl}-2$ homologous antagonist killer; $\mathrm{BAX}, \mathrm{Bcl}-2$-associated $\mathrm{X}$ protein; Bcl, B-cell lymphoma; F, forward; GAPDH, glyceraldehyde-3-phosphate dehydrogenase; PARP, poly-ADP ribose polymerase; PTEN, phosphatase and tensin homologue; $\mathrm{R}$, reverse; TRADD, tumor necrosis factor receptor type 1-associated death domain protein; TRAF, tumor necrosis factor receptor-associated factor.

role in the pathogenesis and progression of GTD. ${ }^{9-11}$ POZ and Krüppel family proteins display essential regulatory functions in many physiological and pathological processes. ${ }^{12}$ Factor that binds to the inducer of short transcripts of HIV-1 [FBI-1, alias POZ and Krüppel erythroid myeloid ontogenic factor $(\mathrm{POKEMON}) / \mathrm{ZBTB} 7 \mathrm{~A} / \mathrm{LRF}]$ is a proto-oncogenic
POZ and Krüppel family transcription repressor on $A R F$ and potentially leads to the inactivation of the p53 pathway. ${ }^{13-15}$ FBI-1 may also play a role in the pathogenesis of GTD.

Aberrant expression of FBI-1 is associated with the cellular transformation of several solid tumors. FBI-1 is overexpressed in cancers of the colon and bladder, in which the normal functions of cyclin-dependent kinase inhibitor $2 \mathrm{~A}$ and $\mathrm{p} 53$ are lost. ${ }^{13,14}$ In contrast, overexpression of FBI-1 has been reported in both p53 mutant and p53 wild-type lung cancer cases. ${ }^{16}$ In ovarian cancer, we previously revealed the oncogenic role of FBI-1 and its ability to induce proliferation and cell migration through direct interaction with the promoter of membrane type 1-matrix metalloproteinase 1 in association with adverse outcome, ${ }^{17}$ suggesting the importance of FBI- 1 in gynecological malignancies and its potential in promoting oncogenesis in diverse molecular pathways more than that formerly described. However, the tumor suppressor activity of FBI-1 has been recently reported in Pten-null prostate tumor models. ${ }^{18}$ The oncogenic role of FBI-1 may therefore be context dependent. Interestingly, an earlier study showed that GTD tends to display high phosphatase and tensin homologue expression. ${ }^{10}$ Hence, the clinical importance and molecular aspects of FBI-1 in GTD deserve an in-depth investigation.

Here, the expression pattern and significance of FBI-1 were evaluated in various types of GTD. The in vitro effects of FBI-1 in relation to apoptosis and cell signaling pathways putatively involved were also investigated. The role of FBI1 in tumor growth was further explored in vivo.

\section{Materials and Methods}

\section{Clinical Samples and Cell Lines}

For immunohistochemistry (IHC) analysis, 87 trophoblastic tissue samples were retrieved from the Department of Pathology, University of Hong Kong, Queen Mary Hospital (Hong Kong, China). These included 17 first-trimester and 9 term placentas, 18 partial and 32 complete moles, eight CCAs, and three placental site trophoblastic tumors. Among 50 hydatidiform moles, 12 developed gestational trophoblastic neoplasm (GTN) requiring chemotherapy. For real-time PCR, snapfrozen samples of 47 hydatidiform moles, 16 first-trimester placentas, and 8 term placentas were also retrieved for cDNA preparation. First-trimester and term placenta were collected after induced abortion by suction evacuation and normal delivery, respectively. The tissues of hydatidiform moles and CCAs were obtained from specimens of uterine evacuate and/ or hysterectomy. The use of such trophoblastic tissues has been approved by the Institutional Review Board of The University of Hong Kong/Hospital Authority Hong Kong West Cluster. All tissue sections were histologically reviewed using generally accepted diagnostic criteria. ${ }^{3,19,20}$ Twenty hydatidiform moles in this series also were previously assessed by fluorescent microsatellite genotyping after microdissection and chromosome in situ hybridization as an adjunct to histological diagnosis. ${ }^{21,22}$ GTN was diagnosed if there 
Table 2 Primary Antibodies Used for Immunoblot Analysis

\begin{tabular}{lllll}
\hline Target protein & Animal source & Catalog \# & Working solution & Vendor \\
\hline FBI-1 & Rabbit & Ab36606 & $1: 1000$ & Abcam Inc. (Cambridge, UK) \\
Actin & Rabbit & A5060 & $1: 1000$ & Sigma (St. Louis, M0) \\
GFP & Mouse & sc-9996 & $1: 1500$ & Santa Cruz Biotechnology, Inc. (Santa Cruz, CA) \\
Akt Total & Mouse & 9272 & $1: 1000$ & Cell Signaling (Beverly, MA) \\
Phospho-Akt (Ser473) & Mouse & 9271 & $1: 1000$ & Cell Signaling \\
p85 $\beta$ & Mouse & ab28356 & $1: 1000$ & Abcam Inc. \\
\hline
\end{tabular}

GFP, green fluorescent protein.

was a plateau in human chorionic gonadotropin level for 4 weeks or a further rise in human chorionic gonadotropin for three consecutive weeks after evacuation.

For in vitro studies, two CCA cell lines (JAR and JEG-3; ATCC, Manassas, VA) and a normal extravillous trophoblast cell line (TEV-1) ${ }^{23}$ were cultured in minimum essential Eagle's medium supplemented with $10 \%$ fetal bovine serum, and $100 \mathrm{U} / \mathrm{mL}$ penicillin and streptomycin.

\section{IHC Analysis}

IHC analysis was performed on deparaffinized sections $5 \mu \mathrm{m}$ thick using the EnVision + Dual Link System (K4061; Dako, Carpinteria, CA $)^{24}$ after antigen retrieval by microwave heating in $0.01 \mathrm{~mol} / \mathrm{L}$ citrate buffer $(\mathrm{pH} 6.0$ ) for 10 minutes. Sections were incubated in peroxidase blocking solution ( $1 \%$ hydrogen peroxide solution) for 5 minutes and washed in phosphate-buffered saline ( $\mathrm{pH}$ 7.4). A polyclonal rabbit antihuman FBI-1 (Pokémon) antibody (catalog no. Ab36606; Abcam, Cambridge, UK) was applied in 1:600 dilution and incubated overnight at room temperature. Freshly prepared 3,3'-diaminobenzidine tetrahydrochloride was applied as chromogen, and sections were counterstained with hematoxylin. Negative controls were prepared by replacing the primary antibody with phosphate-buffered saline. A known positive control from a normal first-trimester placenta was used. ${ }^{24,25}$

Trophoblast subpopulations in each case were evaluated separately. The percentage of positively stained cells was scored according to the following criteria: 0 , no positive staining; 1 , $0.1 \%$ to $25.0 \%$ of cells were positive; $2,25.1 \%$ to $50.0 \%$ of cells were positive; $3,50.1 \%$ to $75.0 \%$ of cells were positive; and 4 , $75.1 \%$ to $100 \%$ of cells were positive. Signal-intensity score was assigned according to the following criteria: 0 , negative staining; 1 , weak staining; 2 , moderate staining; and 3 , strong staining. IHC score, ranging from 0 to 12 , was calculated by multiplying the signal score (0 to 3 ) and the percentage positive score (0 to 4 ). Photomicrographs were taken with the assistance of Spectrum software version 11.1.1.765 (Aperio, Vista, CA).

\section{qPCR}

Real-time quantitative PCR (qPCR) was performed according to previously published procedures. ${ }^{4}$ Total RNA $(2.5 \mu \mathrm{g})$ extracted by TRIzol reagent (Invitrogen/Life Technologies
Inc., Rockville, MD) was subjected to first-strand cDNA synthesis using the SuperScript Reverse Transcriptase system with oligo-dT primers (Invitrogen, Carlsbad, CA). qPCR was performed on the ABI PRISM 7900 Sequence Detection System (Applied Biosystems, Foster City, CA). Unless specified otherwise, the cDNA of GAPDH amplified as housekeeping control for each sample. Primers used are listed in Table 1. The $2^{-\Delta \Delta C T}$ method was used for calculating the relative changes in gene expression determined from qPCR experiments. For in vitro studies, experiments were performed in duplicate and repeated at least twice.

\section{Transfection of FBI-1 Plasmid and siRNA}

JEG-3 and JAR cultures were transfected with FBI-1 construct $^{17}$ using Lipofectamine 2000 (Invitrogen). The pEGFP-C3 vector (Clontech Laboratories, Inc, Mountain View, CA) was used as a control. To knock down FBI-1 in the CCA cell line, Silencer select-predesigned siRNA of FBI-1 (siZBTB7A) (catalog no. 4427037; ID s27988) and nontargeting negative control 2 (scrambled) siRNA (catalog no. 43900846) were used (Ambion, Austin, TX). ${ }^{4,26}$ Transfection with $5 \mathrm{nmol} / \mathrm{L}$ FBI-1-specific/ nontargeting siRNA in siLentFect Lipid Reagent (Bio-Rad Laboratories, Hercules, CA) was performed.

\section{Western Blot Analysis}

Total protein lysate was extracted with sodium dodecyl sulfate lysis buffer containing proteinase inhibitors. ${ }^{4}$ Protein concentration was determined by detergent-compatible protein assay (Bio-Rad). Twenty micrograms of protein was resolved by SDS-polyacrylamide gel electrophoresis, transferred to polyvinylidene difluoride membrane, and probed with corresponding antibodies. The primary antibodies used for Western blot analysis are listed in Table 2.

\section{In Vitro Migration and Invasion Assays}

To determine the impact of FBI-1 on cell mobility, CCA cells transiently transfected with FBI- 1 and corresponding control were counted and equally plated on the upper compartments of 24-well, 8- $\mu \mathrm{m}$ pore size Transwell chambers (BD Biosciences, San Jose, CA). ${ }^{4}$ Cell migration and invasion assays were performed with self-coated gelatin and Matrigel, respectively. After 24 hours, the migrated and 


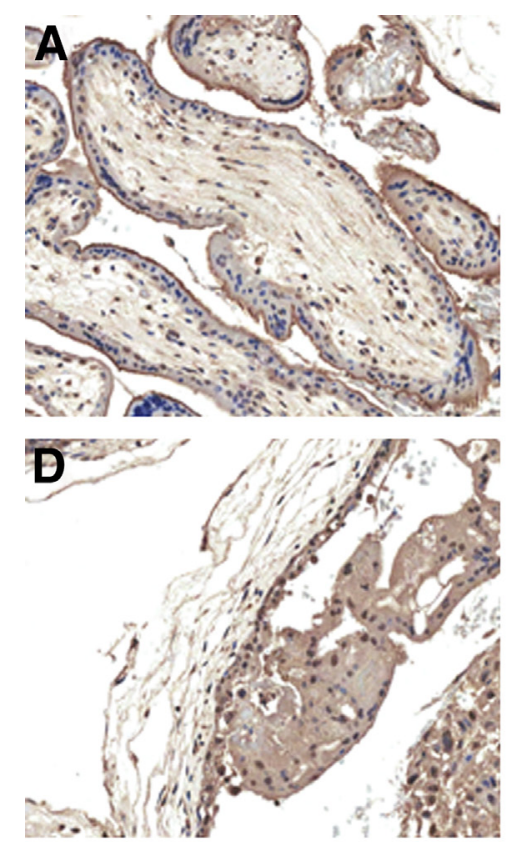

G

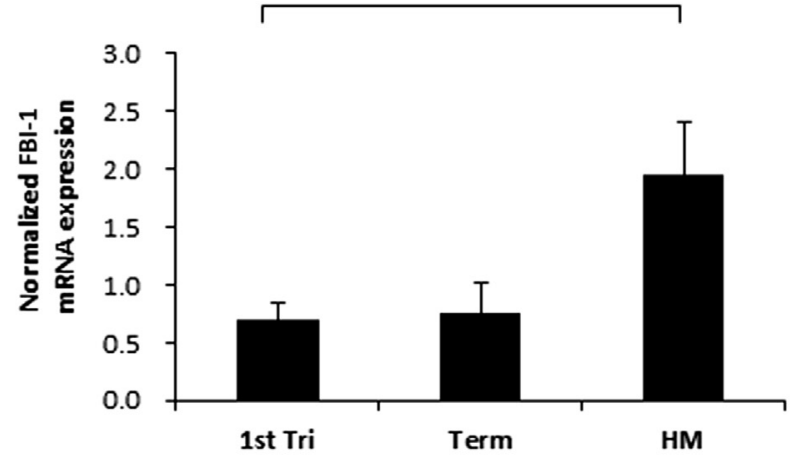

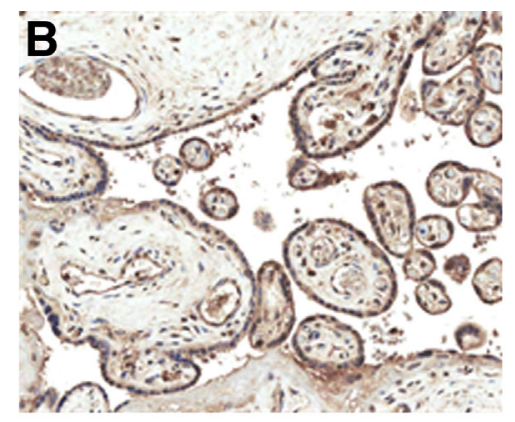
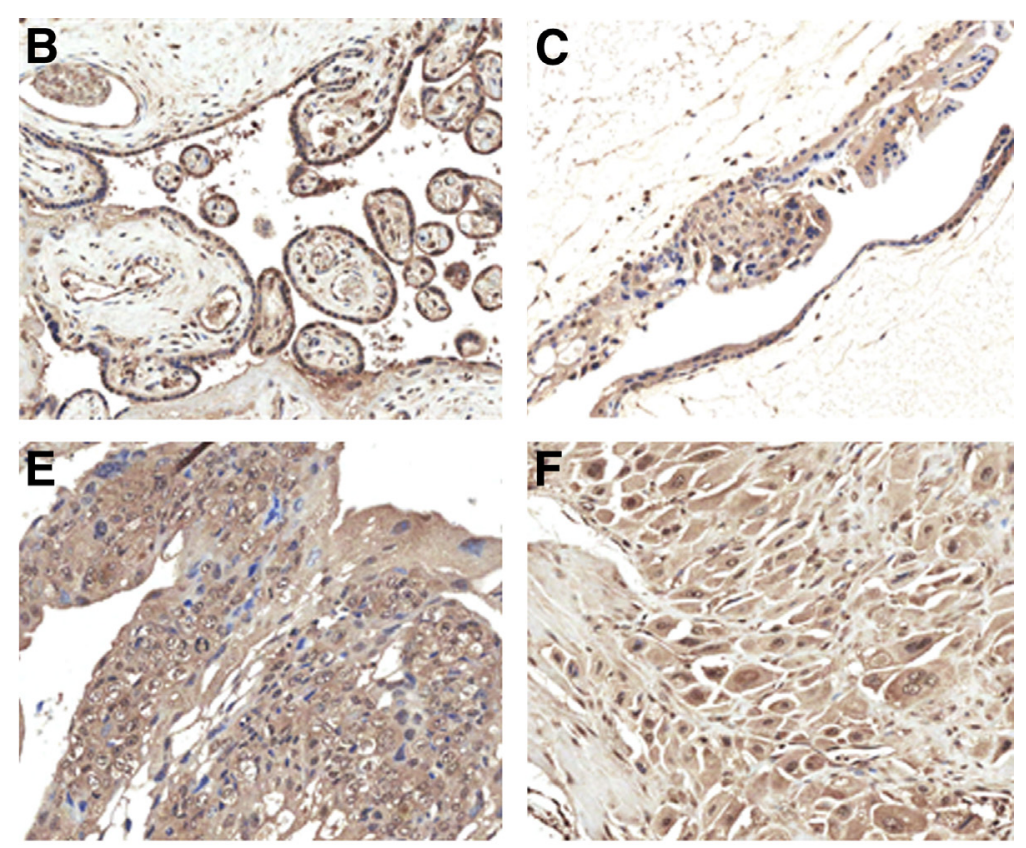

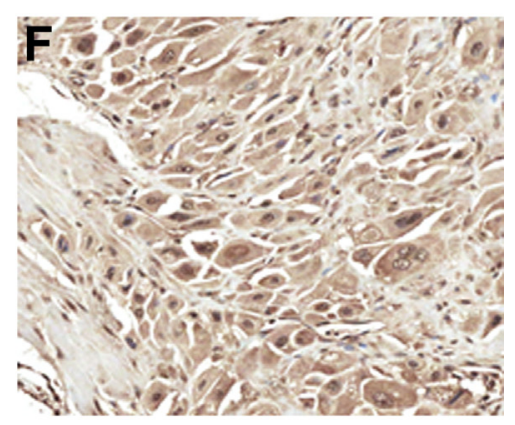

H

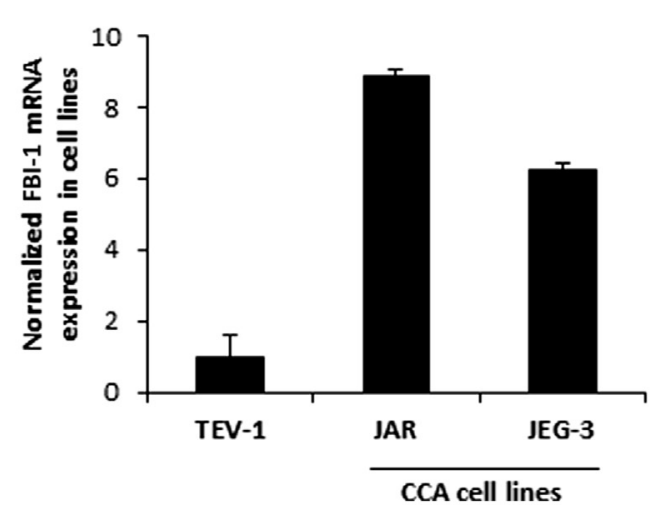

Figure 1 Overexpression of FBI-1 in gestational trophoblastic disease (GTD). A-F: Panel of immunohistochemistry micro-images showing the expression profile of FBI-1 in GTD. Nuclear immunoreactivity is detected in cytotrophoblasts, syncytiotrophoblasts, and villous intermediate trophoblasts of normal firsttrimester (A) and term placentas (B), partial (C) and complete (D) hydatidiform mole (HM) samples, as well as choriocarcinoma (E). High expression is also seen in placental site trophoblastic tumor $(\mathbf{F})$. G: Quantitative real-time PCR analysis shows that FBI-1 mRNA expression significantly increases in HM (including complete and partial moles) compared with first-trimester placenta. FBI-1 mRNA profile in GTD clinical samples was normalized to housekeeping $18 \mathrm{~S}$ rRNA. H: For choriocarcinoma cell lines JAR and JEG-3, overexpression of FBI-1 is observed compared with that in untransformed trophoblast cell line TEV-1. $P=0.015(\mathbf{G}) .{ }^{*} P<0.05$ versus first-trimester placenta. Tri, trimester.

invaded cells on the lower surface of the membrane were fixed and stained with methanol-mixed crystal violet.

For phosphoinositide 3-kinase (PI3K)/Akt pathway study, assays were performed in the presence of $20 \mu \mathrm{mol} / \mathrm{L}$ LY294002. ${ }^{27}$ FBI-1 - or pEGFP-C3-transfected cells were treated with $20 \mu \mathrm{mol} / \mathrm{L}$ LY294002 for 3 hours before cell plating for both migration and invasion assays. Assays were then performed in the presence of the same concentration of inhibitor in the Transwell chamber. Dimethyl sulfoxide was used as control. Each experiment was repeated at least twice. Assays were performed in duplicate wells, and the number of migrated or invaded cells in each well was counted in three randomly selected microscopic fields.

\section{In Vivo Studies of Tumorigenicity of FBI-1}

For in vivo studies of tumorigenicity in CCA cells, human FBI-1-specific shRNA (SureSilencing shRNA constructs) and control shRNA vector (pGeneClip puromycin vector) were purchased from SuperArray (SABiosciences Corporation, Frederick, MD) and transfected into JAR cells under puromycin selection, as published previously. ${ }^{17}$ The $1 \times 10^{6}$ sh-FBI-1 - or vector-transfected CCA cells were inoculated s.c. (six mice per group) into BALB/c female nude mice. All s.c. tumor diameters were measured perpendicularly on days $7,9,11$, and 16 , and volumes were calculated. Mice were sacrificed 18 days after cell injection. 
A
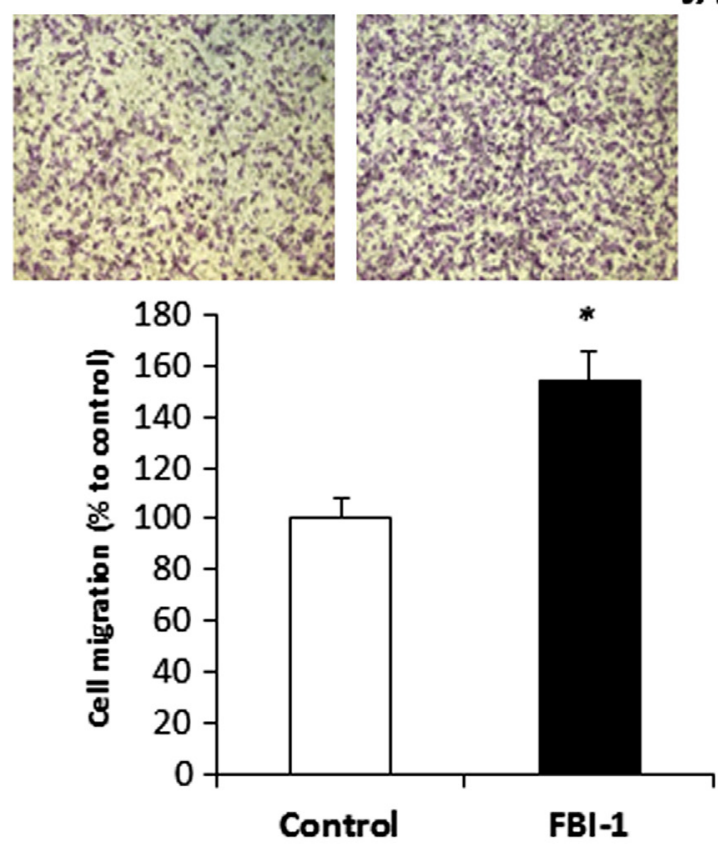

JAR
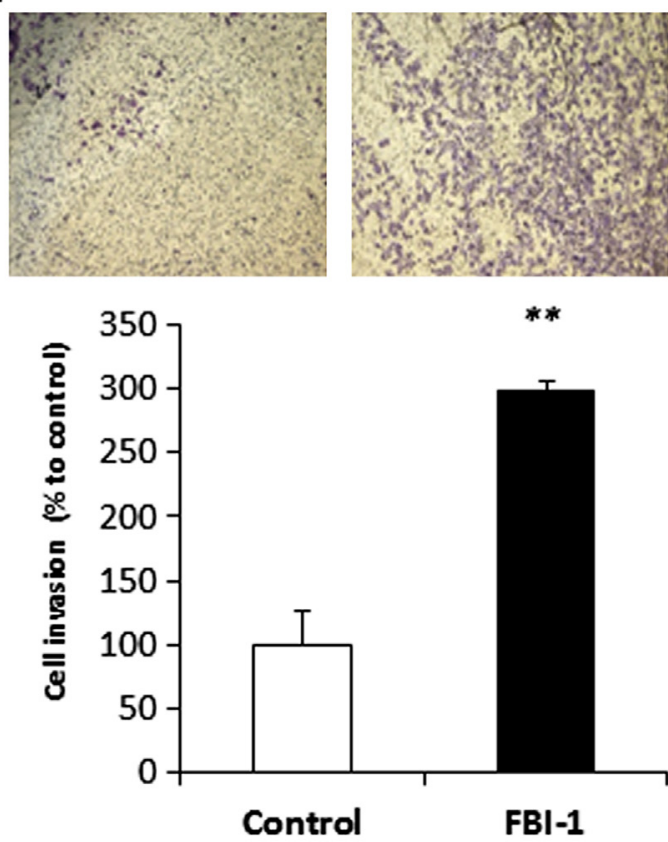

B
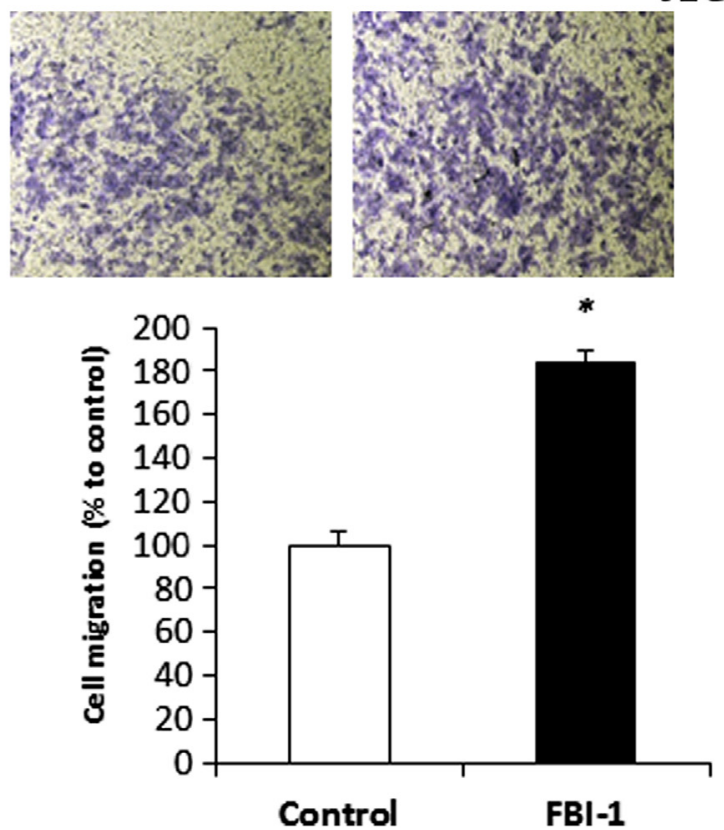

JEG-3
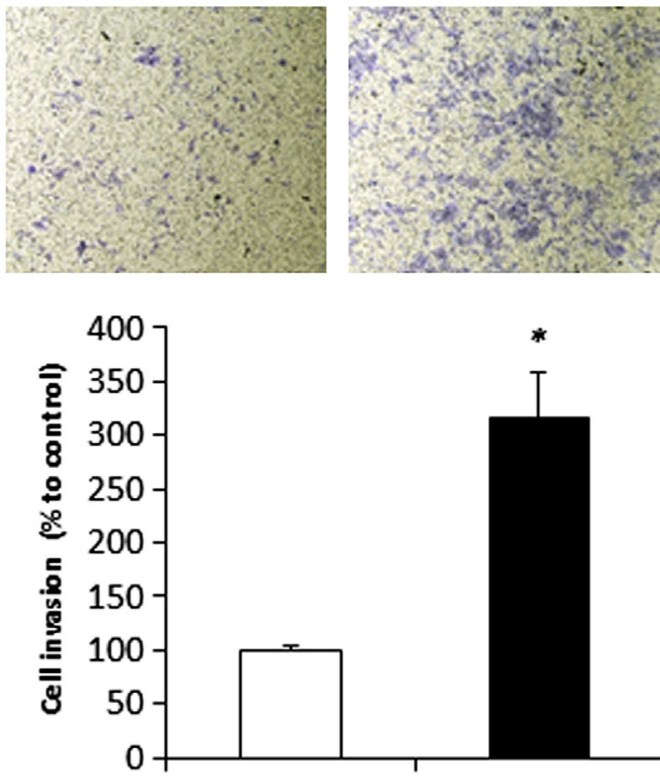

Control

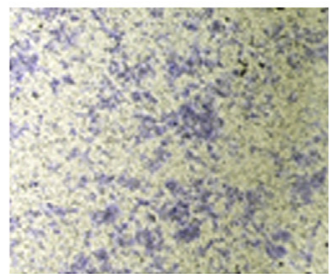

FBI-1

Figure 2 FBI-1 enhances cell migration and invasiveness. Ectopic FBI-1 promotes cell migration and invasiveness of JAR (A) and JEG-3 (B) cells indicated in Transwell migration assay (left panels) and invasion assay (right panels), respectively. ${ }^{\star} P<0.05,{ }^{*} P<0.01$ versus control.

All visible tumors were dissected and the total tumor weight was determined. The animal studies were preformed according to the Animals (Control of Experiments) Ordinance (Hong Kong, China) and the institute's guidance on animal experiments.

\section{Statistical Analysis}

Statistical analysis on nonparametric unpaired $t$-tests for continuous data was performed by SPSS version 15.1 (IBM
SPSS Statistics, IBM Corporation, Armonk, NY). $P<0.05$ was considered statistically significant.

\section{Results}

FBI-1 Is Overexpressed in GTD

IHC studies showed that immunoreactivity of FBI-1 could be detected in the nuclei of cytotrophoblasts, syncytiotrophoblasts, and villous intermediate trophoblasts (Figure 1, A-F). 


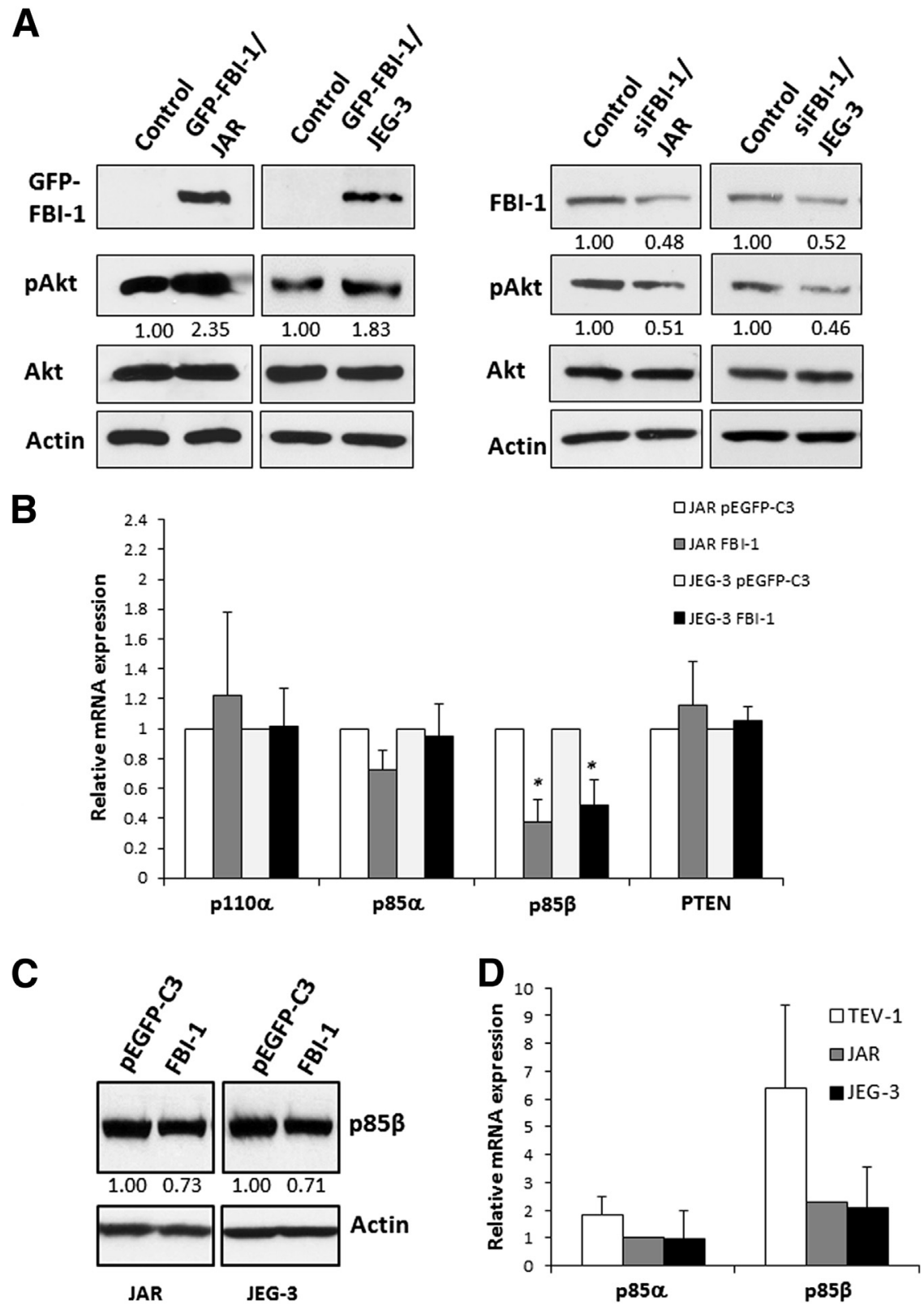

Figure 3 FBI-1 activates Akt associated with p85 $\beta$ suppression. A: Overexpression of FBI- 1 in choriocarcinoma cells promotes Akt activation, as indicated by phosphorylation of Akt at Ser 473 (pAkt-S473). Reciprocal effect on Akt activation is observed by RNA interference using FBI-1 siRNA. B: As revealed by real-time quantitative PCR, among various components in the phosphoinositide 3-kinase (PI3K) pathway, p85 $\beta$ mRNA (PIK3R2) expression is consistently suppressed by ectopic FBI-1. C: Western blot shows reduction in p $85 \beta$ protein level. D: Comparison of p $85 \alpha$ and p $85 \beta$ mRNA expressions between choriocarcinoma cell lines and TEV-1, a normal trophoblast cell line. ImageJ software version 1.48 (NIH, Bethesda, MD) densitometry was used for quantifying Western blots in $\mathbf{A}$ and $\mathbf{C}$. Numbers below protein bands represent relative band intensities normalized to actin, whereas relative intensities of pAkt were normalized to total Akt. ${ }^{*} P<0.05$ versus control. GFP, green fluorescent protein; pEGFP-C3, vector (Clontech Laboratories, Inc.) used as a template to make enhanced green fluorescent protein doublestranded RNA; PTEN, phosphatase and tensin homologue.

Placental site trophoblastic tumor, another malignant type of GTD derived from extravillous implantation site-intermediate trophoblasts, also demonstrated strong nuclear FBI-1 immunoreactivity (Figure $1 \mathrm{~F}$ ).

At the cytotrophoblasts, first-trimester placenta and complete mole samples showed significantly greater FBI-1 immunostaining compared with that of term placenta $(P=0.016$ and $P=0.003$, respectively). At the syncytiotrophoblasts, first-trimester placenta, partial mole, complete mole, and CCA samples showed significantly greater FBI-1 immunostaining compared with that of term placenta $(P<0.001, P=0.003, P<0.001$, and $P=0.006$, respectively). Moreover, FBI-1 immunoscores were significantly greater in complete mole compared with partial mole in cytotrophoblasts $(P=0.002)$, syncytiotrophoblasts $(P=0.005)$, and intermediate trophoblasts $(P=0.004)$.

In hydatidiform mole samples, although FBI immunoscores were numerically greater in cytotrophoblasts and syncytiotrophoblasts in 12 cases that subsequently progressed to GTN compared with those in 20 cases that spontaneously regressed, statistical significance was not reached.

The expression profile of FBI- 1 at mRNA was also examined by qPCR analysis. In normal placenta, first-trimester and term samples had similar FBI-1 mRNA expression. FBI-1 mRNA expression was significantly increased in hydatidiform mole tissue (Figure 1G) compared with that in first-trimester placenta $(P=0.015)$. Overexpression of FBI-1 mRNA was also observed in the CCA cell lines JAR and JEG-3 but not in an immortalized, untransformed TEV-1 sample (Figure 1H). 
A JAR
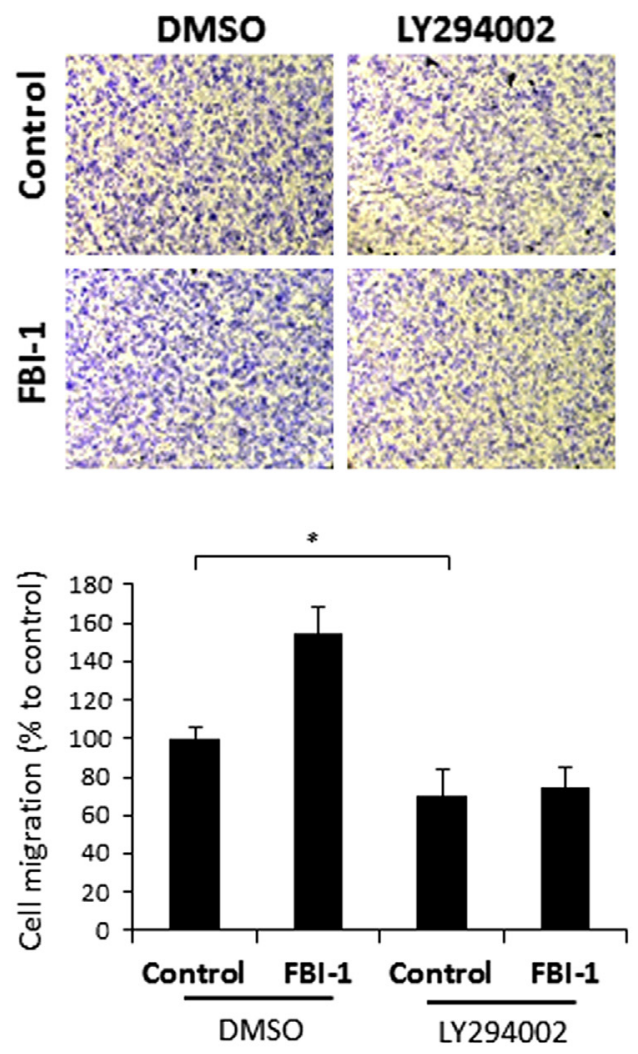

B
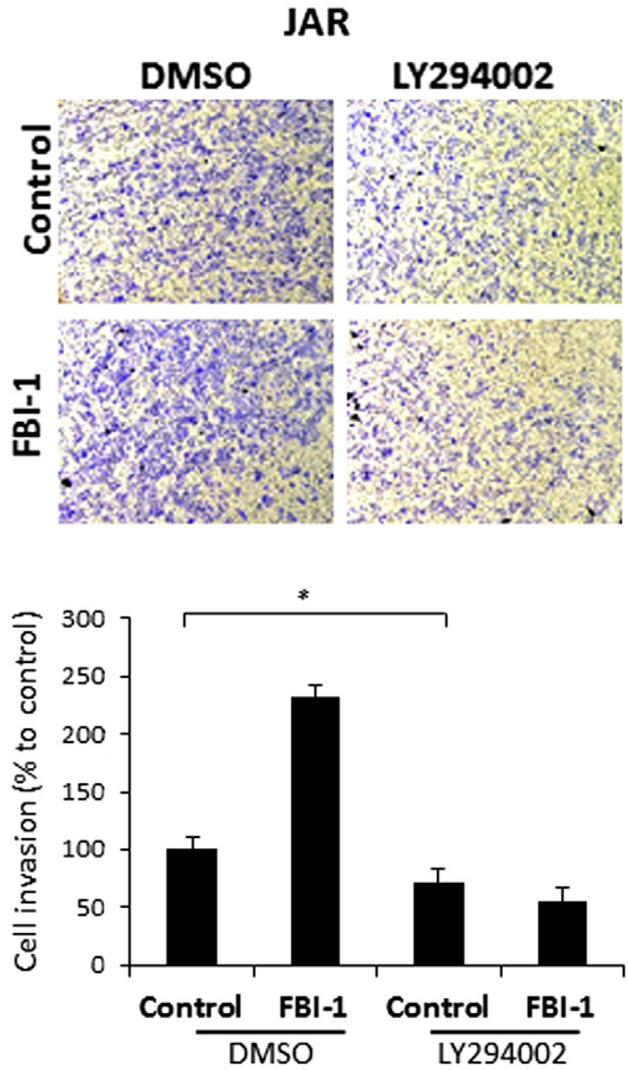

JEG-3
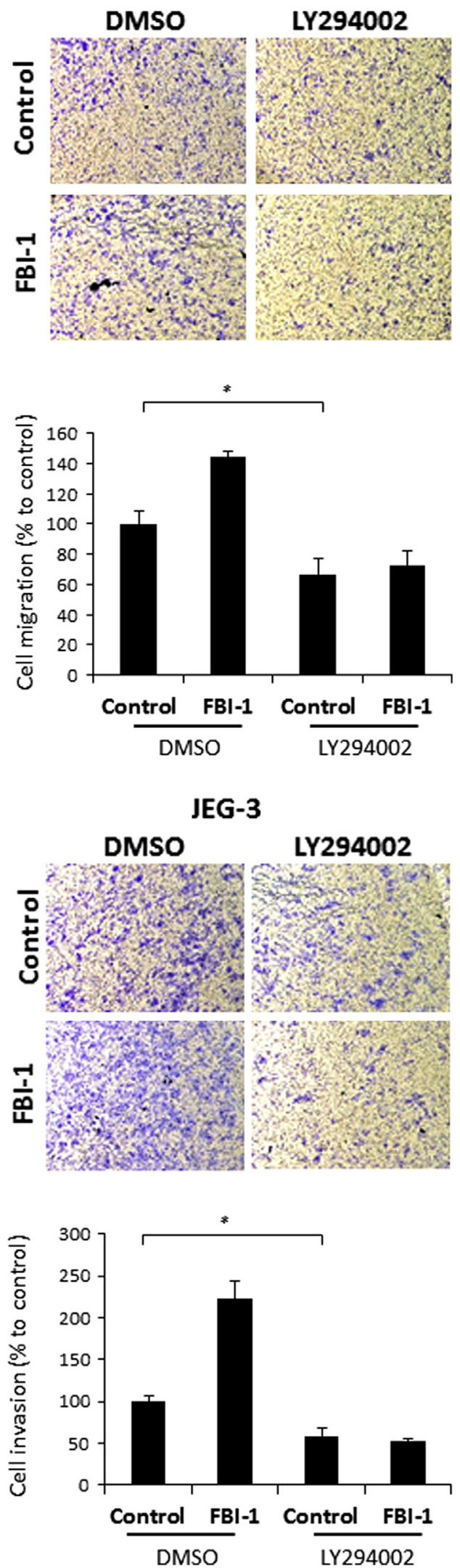

Figure 4 Phosphoinositide 3-kinase (PI3K) inhibitor attenuates the effect of FBI-1 on cell aggressiveness. A: In cell migration assay, administration of 20 mol/L PI3K inhibitor LY294002 prevents FBI-1-mediated enhancement on cell mobility in both JAR and JEG-3 cells. B: In cell invasion assay, inhibition is observed on FBI-1-mediated cell invasiveness of CCA cells in the presence of $20 \mathrm{~mol} / \mathrm{L}$ LY294002. ${ }^{*} P<0.05$ versus dimethyl sulfoxide (DMS0) control. 


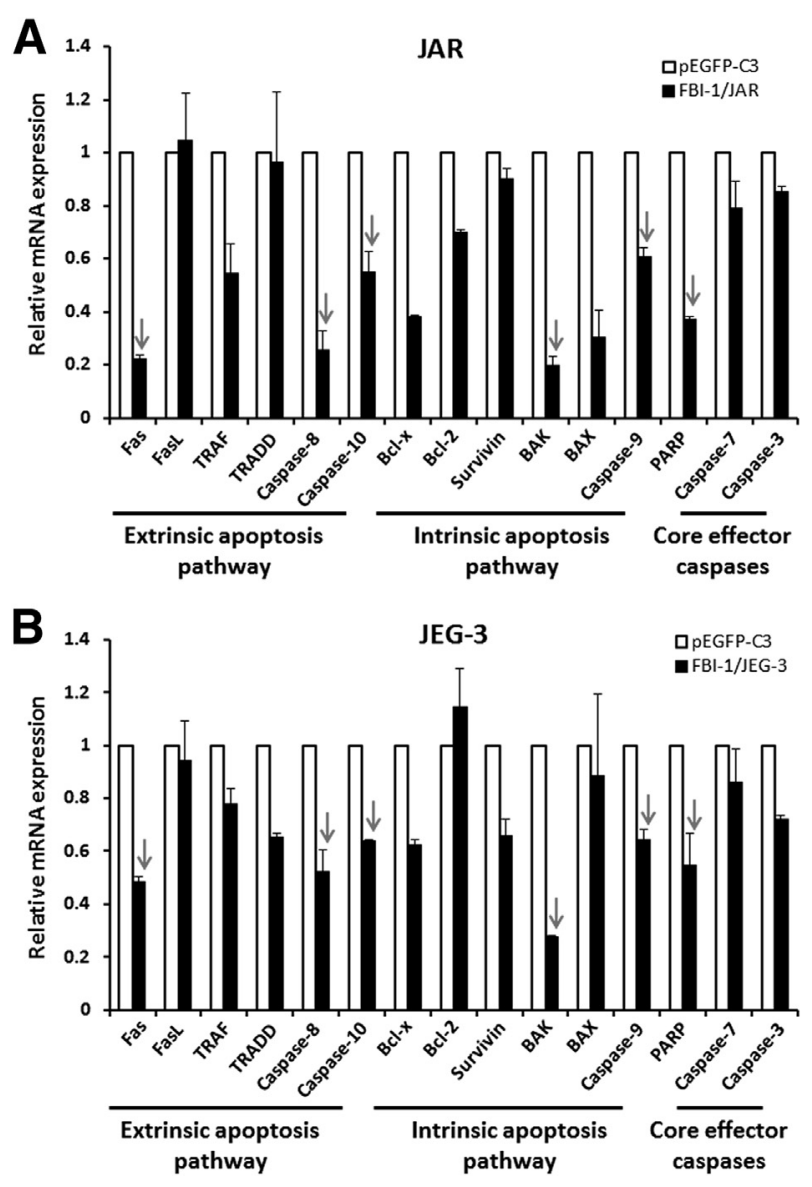

Figure 5 FBI-1 down-regulates proapoptotic genes. Real-time quantitative $\mathrm{PCR}$ shows down-regulation of proapoptotic genes in extrinsic and intrinsic pathways in JAR (A) and JEG-3 (B) cells after FBI-1 overexpression. Arrows indicate proapoptotic genes that were commonly down-regulated in both cell lines. BAK, Bcl-2 homologous antagonist killer; BAX, Bcl-2-associated $X$ protein; $\mathrm{BCl}$, B-cell lymphoma; PARP, poly-ADP ribose polymerases; $\mathrm{pEGFP-}$ C3, vector (Clontech Laboratories, Inc.) used as a template to make enhanced green fluorescent protein fused to $\mathrm{C}$-terminus of the transfected gene product; TRADD, tumor necrosis factor receptor type 1-associated death domain protein; TRAF, tumor necrosis factor receptor-associated factor.

\section{Ectopic FBI-1 Promotes Cell Migration and Invasion in Vitro}

JEG-3 and JAR cell lines were transiently transfected with FBI-1 and assessed for cell mobility and invasiveness in Transwell assay. FBI-1 overexpression was significantly associated with the promotion of cell migration and invasion in both CCA cell lines (all $P<0.05$ ). On cell migration assay, increases in cell motility of about 1.5- and 1.8-fold were observed in JAR and JEG-3, respectively (Figure 2). On the other hand, cell invasiveness increased by threefold subsequent to overexpression of FBI-1 in both cell lines (Figure 2).

\section{Akt Activation by FBI-1}

Akt activation stimulates cell survival, metabolism, and migration through its ability to phosphorylate its downstream targets. ${ }^{28,29}$ Here we investigated the potential relationship between FBI-1 and Akt activation in JAR and JEG-3. The level of a phosphorylated form of Akt at Ser 473 (pAkt-S473) was used as the readout of Akt activation on Western blot. Strikingly, Akt was activated, as indicated by increased expression of pAkt-S473 on ectopic overexpression of FBI-1, whereas no change in total Akt expression was observed (Figure 3A). On the other hand, knockdown of FBI-1 using the siRNA approach led to a decreased level of pAkt-S473 in transfected JEG-3 and JAR (Figure 3A).

Hyperactivation of Akt is frequently brought by aberrant regulation of the upstream PI3K signaling pathway in a wide range of human cancers. ${ }^{30}$ The major Class I PI3K is composed of a p110 catalytic subunit and a p85 regulatory subunit. To date, several p85 subunits have been identified in which $\mathrm{p} 85 \alpha$ and $\mathrm{p} 85 \beta$ are the two major isoforms. ${ }^{31}$ The p110-PI3K enzyme phosphorylates Akt through the generation of the key signaling lipid phosphatidylinositol 3,4,5trisphosphate.

To dissect the mechanism of regulation of Akt phosphorylation by FBI-1, we investigated the expression of several regulatory components by qPCR, including p110 $\alpha$ (encoded by PIK3CA), p85 $\alpha$ (PIK3RI), p85 $\beta$ (PIK3R2), and phosphatase and tensin homologue involved in the PI3K pathway. Results showed that ectopic FBI-1 exerted a significant suppression of $\mathrm{p} 85 \beta$ but not $\mathrm{p} 85 \alpha$ in both JAR and JEG-3 (Figure 3B). At the protein level, a reduction in $\mathrm{p} 85 \beta$ in response to ectopic FBI-1 was also observed (Figure 3C). With regard to the role of $\mathrm{p} 85 \beta$ in CCA cells, its basal mRNA expression level was compared between JAR and JEG-3 and immortalized, untransformed TEV-1. p $85 \beta$ mRNA expression was significantly less in JEG-3 and JAR compared with TEV-1 (Figure 3D), contrasting the expression profile of proto-oncogenic FBI-1 in the cell lines examined (Figure 1H).

\section{FBI-1-Enhanced Cell Motility and Invasion Are Mediated by the PI3K/Akt Pathway}

The PI3K inhibitor LY294002 is highly selective. ${ }^{32}$ The effects of FBI-1 on cell migration and invasion with the administration of LY294002 were investigated to unveil the potential interaction between FBI-1 and the PI3K/Akt pathway. Consistent with the findings in Ectopic FBI-1 Promotes Cell Migration and Invasion in Vitro (Figure 2), ectopic expression of FBI-1 promoted cell migration (Figure 4A) and invasion (Figure 4B) in both CCA cell lines with mock treatment (dimethyl sulfoxide). In contrast, ectopic FBI-1 failed to promote cell migration and invasion in the presence of $20 \mu \mathrm{mol} / \mathrm{L}$ LY294002. These data strongly suggest that FBI-1 can regulate these two aggressive phenotypes through the PI3K/Akt signaling pathway and highlight the importance of novel FBI-1-induced Akt activation.

\section{Antiapoptotic Nature of FBI-1}

Intrinsic and extrinsic apoptotic pathways are two important components in apoptosis. Aberrantly expressed apoptotic 


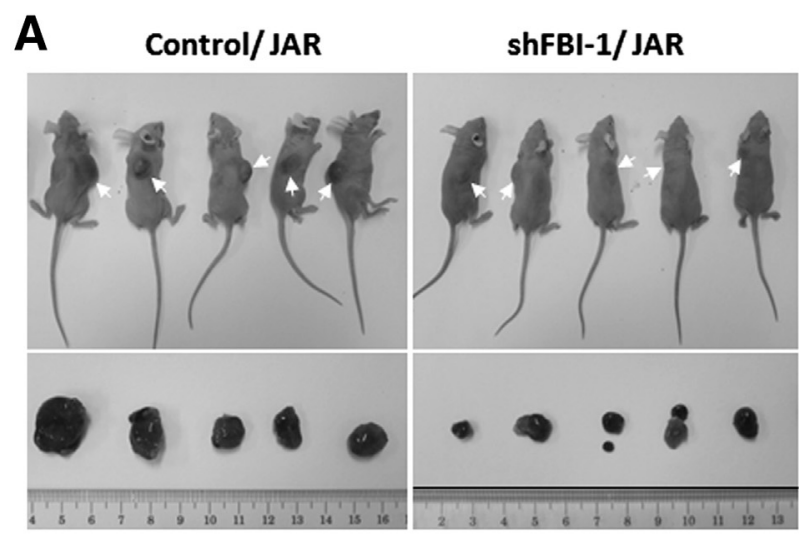

B

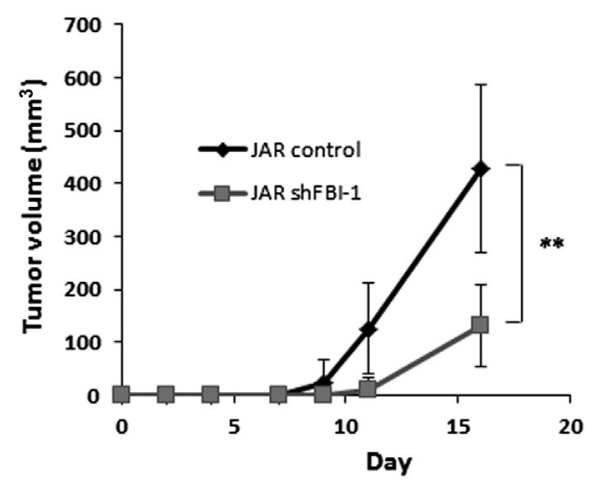

C

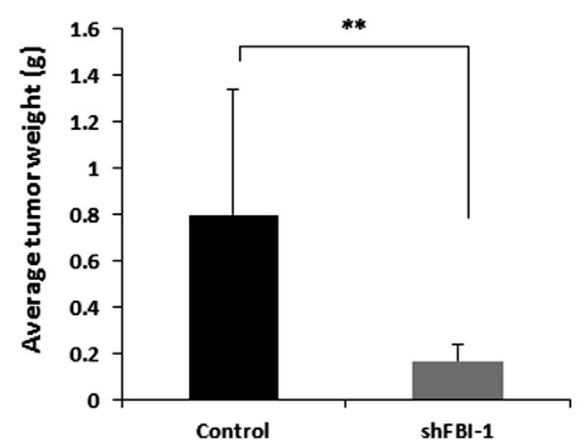

Figure 6 FBI-1 knockdown choriocarcinoma cells reduce tumor growth in vivo. A: Dissected s.c. tumors from mice inoculated with sh-FBI-1 JAR and control cells, respectively. Arrows indicate tumors developed at injection sites. B and C: Growth rate (B) and final weight (means \pm SD; C) of s.c. tumors formed in nude mice inoculated with sh-FBI-1 JAR cells are less than those in control cells. ${ }^{* *} P<0.01$ versus control.

pathway components or regulators may prevent apoptosis. ${ }^{9}$ Surprisingly, on qPCR analysis, subsequent down-regulation of a broad range of proapoptotic genes involved in the extrinsic and intrinsic pathways of apoptosis at the transcript level, such as FAS, CASP8, CASp10, BAK, CASP9, as well as poly-ADP ribose polymerases, was demonstrated in FBI1-transfected JAR and JEG-3 (Figure 5), demonstrating a potent antiapoptotic nature of FBI-1 in apoptosis regulation.

\section{Effects of FBI-1 on Tumor Growth in Vivo}

To investigate the in vivo effects of FBI-1, sh-FBI-1 JAR, sh-FBI-1 JEG-3, and control cells (sh-Negative Control) were prepared and inoculated s.c. to nude mice. The growth rate of s.c. tumors formed in mice inoculated with sh-FBI-1 CCA cells was significantly less than that in tumors formed by control cells (Figure 6, A and B). The total s.c. tumor weight was significantly less in the sh-FBI-1 CCA cell-injected mice than in the control mice $(0.169 \pm 0.073 \mathrm{~g}$ versus $0.8 \pm 0.543 \mathrm{~g} ; P=0.009$ ) (Figure $6 \mathrm{C}$ ).

\section{Discussion}

Placental trophoblasts form a pseudomalignant tissue carrying proper proliferating and invasive potentials for maternal endometrial invasion. ${ }^{33}$ Any uncontrolled trophoblastic growth may result in pathological conditions. GTD is a proliferative disorder of placental trophoblasts with excessive apoptosis and proliferation and dysregulated signaling pathways. ${ }^{2,5}$ Among distinct clinicopathological forms of GTD, GTNs usually harbor aggressive invasive and metastatic capabilities that may lead to death if GTN is left untreated. ${ }^{34}$

Here, we demonstrated the diverse oncogenic properties of FBI- 1 and its expression profile in GTD. FBI- 1 is overexpressed in various forms of GTD, including hydatidiform mole, CCA, and placental site trophoblastic tumor. Emerging studies have suggested that hyperactivation of oncogenic signaling pathways tend to contribute invasive phenotype of the trophoblasts in GTD. For example, we have previously demonstrated that overexpression of the p21-activated kinase 1 is involved in the pathogenesis of GTD. ${ }^{4}$ Cell signaling studies further showed that overexpressed p21-activated kinase 1 promoted cell migration and invasion in CCA cells. Thus, it is tempting to address whether FBI-1, which is also overexpressed in GTD, is involved in these aggressive cellular behaviors via oncogenic signaling pathway activation.

The PI3K/Akt signaling pathway is a central physiological pathway that is frequently hyperactivated in solid tumors. ${ }^{35}$ This study demonstrated that FBI-1 would be one of the upstream regulators of Akt activation in CCA. Ectopic FBI-1 could induce the activation of Akt, as indicated by the increased level of pAkt-S473, whereas the opposite effect was observed in FBI-1 knockdown. Although potential involvement of FBI-1 in the Akt pathway was also shown in hepatocellular carcinoma during the preparation of this article,$^{36}$ it is apparent that FBI-1 promoted cell proliferation and migration only in hepatocellular carcinoma cells. ${ }^{36,37}$ In contrast, our earlier report in ovarian cancer illustrated that FBI-1 also played an important role in cell invasion. ${ }^{17}$ Hence, the oncogenic consequences of aberrantly expressed FBI-1, especially the effect on cell invasion, may vary in different solid tumors.

Little is known about the effects of the FBI-1/Akt pathway on trophoblast invasiveness and the mechanistic link between FBI-1 and the Akt pathway. The present study investigated several regulatory components involved in the PI3K pathway. Results showed that FBI-1 significantly down-regulated $\mathrm{p} 85 \beta$ 
expression in CCA cell lines. Meanwhile, cell line comparison showed that $\mathrm{p} 85 \beta$ expression was reduced in CCA cell lines compared with that in normal trophoblasts, suggesting that FBI-1 induced Akt activation through down-regulation of $\mathrm{p} 85 \beta$. Further experimental studies of these novel interactions may help to elucidate the regulatory effects of FBI-1 on the Akt pathway. Strikingly, in the presence of PI3K inhibitor, FBI-1 failed to enhance both cell migration and cell invasion in JEG-3 and JAR cells. As a result, our findings strongly suggest that dysregulated FBI-1 expression would affect both cell invasion and migration capabilities through PI3K/Akt signaling in GTD and hence contribute to the aggressive nature of GTN when it is overexpressed.

The proto-oncogenic effects of FBI-1 were not restricted in trophoblast migration and invasion. An earlier report suggested that FBI-1 represses transcription of $\mathrm{p} 21^{\mathrm{Cip} 1}$ by inhibition of transcription activation by $\mathrm{p} 53$ and Sp1, highlighting the potent transcriptional repression activity on the p53 pathway. ${ }^{15}$ In GTD, p53-related genes or regulators play crucial roles in modulating apoptosis during disease progression. ${ }^{9,11}$ Also, the involvement of these regulators in crosstalk between apoptosis and the cell signaling pathway in GTD may result in an adverse clinical outcome. For example, we have previously demonstrated that proapoptotic apoptosisstimulating protein of p53 2 is down-regulated in highly metastatic CCA and contributes to increased migratory potential through the activation of the Src signaling pathway. ${ }^{11}$ Interestingly, our qPCR analysis of apoptotic genes in FBI1-transfected CCA cells revealed an unreported downregulation of a broad range of proapoptotic genes in both intrinsic and extrinsic pathways, including death receptor $F A S$, apoptosis-initiating $B A K$, initiator caspases (CASP8, CASP9, and $C A S P 10$ ), as well as apoptosis-executing poly-ADP ribose polymerases (Figure 5). FBI-1-induced down-regulation of these proapoptotic gene transcripts implicates the ability of FBI-1 to manipulate apoptosis cassette/machineries and to hence protect cells from apoptosis in GTD.

The in vivo studies clearly have shown that knockdown of FBI- 1 could reduce the tumor growth of CCA cells in nude mice. These findings not only demonstrate the oncogenic nature of FBI-1 but also hint that targeting FBI-1 would be promising in attenuating CCA growth. With regard to the clinical management of GTN, FBI-1 may have potential therapeutic value. GTNs can be subclassified as low-risk or high-risk diseases that require different chemotherapy regimens. Patients with high-risk GTN usually develop drug resistance to monochemotherapy. ${ }^{34}$ Targeting the multifunctional FBI-1 may be therefore a novel therapeutic approach to GTN. In fact, the capability of FBI-1 to enhance chemotherapy resistance in vivo has also been recently suggested in some solid tumors. ${ }^{37}$ It will be interesting to further investigate the expression and function of FBI-1 in those rare recurrent and chemoresistant cases of GTN. ${ }^{38}$

In conclusion, we have shown that FBI-1 is overexpressed in GTD. Its overexpression exerts diverse oncogenic effects on the dysregulated trophoblasts in GTD, including promoting cell migration and invasion and protecting cells from apoptosis.

\section{References}

1. Cheung AN: Pathology of gestational trophoblastic diseases. Best Pract Res Clin Obstet Gynaecol 2003, 17:849-868

2. Shih Ie M: Gestational trophoblastic neoplasia-pathogenesis and potential therapeutic targets. Lancet Oncol 2007, 8:642-650

3. Shih I, Mazur M, Kurman R: Gestational trophoblastic disease and related lesions. Edited by Kurman RJ. Blaustein's Pathology of the Female Genital Tract. New York, Springer, 2002, pp 1193-1250

4. Siu MK, Yeung MC, Zhang H, Kong DS, Ho JW, Ngan HY, Chan DC, Cheung AN: p21-Activated kinase-1 promotes aggressive phenotype, cell proliferation, and invasion in gestational trophoblastic disease. Am J Pathol 2010, 176:3015-3022

5. Cheung AN, Zhang HJ, Xue WC, Siu MK: Pathogenesis of choriocarcinoma: clinical, genetic and stem cell perspectives. Future Oncol 2009, 5: 217-231

6. Chiu PM, Ngan YS, Khoo US, Cheung AN: Apoptotic activity in gestational trophoblastic disease correlates with clinical outcome: assessment by the caspase-related M30 CytoDeath antibody. Histopathology 2001, 38:243-249

7. Xue WC, Khoo US, Ngan HY, Chan KY, Chiu PM, Tsao SW, Cheung AN: Minichromosome maintenance protein 7 expression in gestational trophoblastic disease: correlation with Ki67, PCNA and clinicopathological parameters. Histopathology 2003, 43:485-490

8. Cheung AN, Srivastava G, Chung LP, Ngan HY, Man TK, Liu YT, Chen WZ, Collins RJ, Wong LC, Ma HK: Expression of the p53 gene in trophoblastic cells in hydatidiform moles and normal human placentas. J Reprod Med 1994, 39:223-227

9. Mak VC, Lee L, Siu MK, Wong OG, Lu X, Ngan HY, Wong ES, Cheung AN: Downregulation of ASPP1 in gestational trophoblastic disease: correlation with hypermethylation, apoptotic activity and clinical outcome. Mod Pathol 2011, 24:522-532

10. Zhang HJ, Siu MK, Jiang LL, Mak VC, Ngan HY, Cheung AN: Overexpression of the Parkinson disease protein DJ-1 and its regulator PTEN in gestational trophoblastic disease. Int J Gynecol Pathol 2010, 29:468-475

11. Mak VC, Lee L, Siu MK, Wong OG, Lu X, Ngan HY, Wong ES, Cheung AN: Downregulation of ASPP2 in choriocarcinoma contributes to increased migratory potential through Src signaling pathway activation. Carcinogenesis 2013, 34:2170-2177

12. Costoya JA: Functional analysis of the role of POK transcriptional repressors. Brief Funct Genomic Proteomic 2007, 6:8-18

13. Maeda T, Hobbs RM, Pandolfi PP: The transcription factor Pokemon: a new key player in cancer pathogenesis. Cancer Res 2005, 65:8575-8578

14. Maeda T, Hobbs RM, Merghoub T, Guernah I, Zelent A, Cordon-Cardo C, Teruya-Feldstein J, Pandolfi PP: Role of the proto-oncogene Pokemon in cellular transformation and ARF repression. Nature 2005, 433:278-285

15. Choi WI, Jeon BN, Yun CO, Kim PH, Kim SE, Choi KY, Kim SH, Hur MW: Proto-oncogene FBI-1 represses transcription of p21CIP1 by inhibition of transcription activation by $\mathrm{p} 53$ and Sp1. J Biol Chem 2009, 284:12633-12644

16. Apostolopoulou K, Pateras IS, Evangelou K, Tsantoulis PK, Liontos M, Kittas C, Tiniakos DG, Kotsinas A, Cordon-Cardo C, Gorgoulis VG: Gene amplification is a relatively frequent event leading to ZBTB7A (Pokemon) overexpression in non-small cell lung cancer. J Pathol 2007, 213:294-302

17. Jiang L, Siu MK, Wong OG, Tam KF, Lam EW, Ngan HY, Le XF, Wong ES, Chan HY, Cheung AN: Overexpression of proto-oncogene FBI-1 activates membrane type 1-matrix metalloproteinase in association with adverse outcome in ovarian cancers. Mol Cancer 2010, 9:318

18. Wang G, Lunardi A, Zhang J, Chen Z, Ala U, Webster KA, Tay Y, Gonzalez-Billalabeitia E, Egia A, Shaffer DR, Carver B, Liu XS, 
Taulli R, Kuo WP, Nardella C, Signoretti S, Cordon-Cardo C, Gerald WL, Pandolfi PP: Zbtb7a suppresses prostate cancer through repression of a Sox9-dependent pathway for cellular senescence bypass and tumor invasion. Nat Genet 2013, 45:739-746

19. Cheung A: Gestational trophoblastic disease. Robboy's Pathology of the Female Reproductive Tract. Edited by Robboy S, Mutter G, Prat J, Bentley R, Russell P, Anderson M. China, Elsevier Churchill Livingstone, 2009, pp 881-907

20. Paradinas F, Elston C: Gestational trophoblastic disease. Haines and Taylor: Obstetrical and Gynaecological Pathology. Edited by Fox H, Wells M. Edinburgh, Churchill Livingstone, 2003, pp 1359-1430

21. Cheung AN, Khoo US, Lai CY, Chan KY, Xue WC, Cheng DK, Chiu PM, Tsao SW, Ngan HY: Metastatic trophoblastic disease after an initial diagnosis of partial hydatidiform mole: genotyping and chromosome in situ hybridization analysis. Cancer 2004, 100:1411-1417

22. Lai CY, Chan KY, Khoo US, Ngan HY, Xue WC, Chiu PM, Tsao SW, Cheung AN: Analysis of gestational trophoblastic disease by genotyping and chromosome in situ hybridization. Mod Pathol 2004, 17: $40-48$

23. Feng HC, Choy MY, Deng W, Wong HL, Lau WM, Cheung AN, Ngan HY, Tsao SW: Establishment and characterization of a human firsttrimester extravillous trophoblast cell line (TEV-1). J Soc Gynecol Investig 2005, 12:e21-e32

24. Chan HY, Siu MK, Zhang HJ, Wong ES, Ngan HY, Chan KY, Cheung AN: Activated Stat3 expression in gestational trophoblastic disease: correlation with clinicopathological parameters and apoptotic indices. Histopathology 2008, 53:139-146

25. Siu MK, Wong ES, Chan HY, Ngan HY, Chan KY, Cheung AN: Overexpression of NANOG in gestational trophoblastic diseases: effect on apoptosis, cell invasion, and clinical outcome. Am J Pathol 2008, 173: $1165-1172$

26. Siu MK, Wong ES, Kong DS, Chan HY, Jiang L, Wong OG, Lam EW, Chan KK, Ngan HY, Le XF, Cheung AN: Stem cell transcription factor NANOG controls cell migration and invasion via dysregulation of E-cadherin and FoxJ1 and contributes to adverse clinical outcome in ovarian cancers. Oncogene 2013, 32:3500-3509
27. Liu P, Xu B, Li J, Lu H: LY294002 inhibits leukemia cell invasion and migration through early growth response gene 1 induction independent of phosphatidylinositol 3-kinase-Akt pathway. Biochem Biophys Res Commun 2008, 377:187-190

28. Cantley LC: The phosphoinositide 3-kinase pathway. Science 2002, 296:1655-1657

29. Yuan TL, Cantley LC: PI3K pathway alterations in cancer: variations on a theme. Oncogene 2008, 27:5497-5510

30. Hennessy BT, Smith DL, Ram PT, Lu Y, Mills GB: Exploiting the PI3K/AKT pathway for cancer drug discovery. Nat Rev Drug Discov 2005, 4:988-1004

31. Taniguchi CM, Tran TT, Kondo T, Luo J, Ueki K, Cantley LC, Kahn CR: Phosphoinositide 3-kinase regulatory subunit p85alpha suppresses insulin action via positive regulation of PTEN. Proc Natl Acad Sci U S A 2006, 103:12093-12097

32. Vlahos CJ, Matter WF, Hui KY, Brown RF: A specific inhibitor of phosphatidylinositol 3-kinase, 2-(4-morpholinyl)-8-phenyl-4H-1benzopyran-4-one (LY294002). J Biol Chem 1994, 269:5241-5248

33. Ferretti C, Bruni L, Dangles-Marie V, Pecking AP, Bellet D: Molecular circuits shared by placental and cancer cells, and their implications in the proliferative, invasive and migratory capacities of trophoblasts. Hum Reprod Update 2007, 13:121-141

34. Alifrangis C, Seckl MJ: Genetics of gestational trophoblastic neoplasia: an update for the clinician. Future Oncol 2010, 6:1915-1923

35. Samuels Y, Ericson K: Oncogenic PI3K and its role in cancer. Curr Opin Oncol 2006, 18:77-82

36. Lin CC, Zhou JP, Liu YP, Liu JJ, Yang XN, Jazag A, Zhang ZP, Guleng B, Ren JL: The silencing of Pokemon attenuates the proliferation of hepatocellular carcinoma cells in vitro and in vivo by inhibiting the PI3K/Akt pathway. PLoS One 2012, 7:e51916

37. Fang F, Yang L, Tao Y, Qin W: FBI-1 promotes cell proliferation and enhances resistance to chemotherapy of hepatocellular carcinoma in vitro and in vivo. Cancer 2012, 118:134-146

38. Newlands ES: The management of recurrent and drug-resistant gestational trophoblastic neoplasia (GTN). Best Pract Res Clin Obstet Gynaecol 2003, 17:905-923 